\title{
Legal Issues and Challenges in Managing Kuala Lumpur as a Tourism Destination: A case study of the Silang Street
}

\author{
Siti Sarah Sulaiman ${ }^{1}$, Nur Ezan Rahmat ${ }^{1}$, Najwa Azizun ${ }^{2}$ \\ ${ }^{1}$ Faculty of Law, Universiti Teknologi MARA, Shah Alam, Selangor, Malaysia \\ 2 Universiti Teknologi MARA, Dengkil, Selangor, Malaysia \\ sitisarahsulaiman@gmail.com, nurezanrahmat@gmail.com, najwa6483@uitm.edu.my \\ Tel: +6019-3951878
}

\begin{abstract}
Kuala Lumpur is a historical city with heritage significance for tourism destination. However, the heritage significance of the city may be challenged by several issues. One of which is the number of immigrants who have manipulated business activities in the busy street which is known as Silang Street. The issue of immigrants at Silang Street is not only on the matter of licence to operate business, but also involved the immigration aspect. This paper highlights the challenges faced by the stakeholders in regulating business activities conducted by the immigrants at Silang Street and possible improvements are suggested.
\end{abstract}

Keywords: heritage; Kuala Lumpur; legal issues; tourism destination

eISSN: 2398-4287 @ 2020. The Authors. Published for AMER ABRA cE-Bs by e-International Publishing House, Ltd., UK. This is an open access article under the CC BYNC-ND license (http://creativecommons. org/licenses/by-nc-nd/4.0). Peer-review under responsibility of AMER (Association of Malaysian Environment-Behaviour Researchers), ABRA (Association of Behavioural Researchers on Asians) and cE-Bs (Centre for Environment-Behaviour Studies), Faculty of Architecture, Planning \& Surveying, Universiti Teknologi MARA, Malaysia.

DOI: https://doi.org/10.21834/ebpj.v5iSI1.2321

\subsection{Introduction}

Tourism plays an important role in contributing towards the development of the economy in every country. In Malaysia, tourism is considered as the second highest contributor to the Gross Domestic Product (GDP) after manufacturing (M. Motasim, 2014). Norsiah Kadir and M. Zaini Abd Karim (2012) suggests that the tourism industry is a significant contributor to the economic growth in Malaysia. This is supported by another research by Tang, C.F \& Tan, E.C., (2015) which highlighted that economic growth, tourism and other determinants are co-integrated. One of the recognised factors affecting destination choice is known as perceived risks (Chew, E.Y.T \& Jahari, S.A. 2014; Sharifpour, M. et.al, 2014; Yang, E.C.L \& Nair, V.; Yang, E.C.L. et al, 2015). The risks have been identified and categorised as man-made disasters and natural disasters (Ruan, W.Q. et al, 2017). Man-made disasters include terrorist attacks, political instability, intense traffic, litter, oil seepage and water quality. While natural disaster refers to earthquakes, volcanic eruptions, floods, tsunamis and cyclones. All these factors may deter tourists' travel intentions.

Silang Street is included as part of the heritage trail which one of the projects in Kuala Lumpur City Centre (Yip Yoke Teng, 2013). The River of Life (ROL) was identified in the Klang Valley National Key Economic Area under the Economic Transformation Programme. It aims to transform the Klang and Gombak River into an active and liveable riverfront with high economic value by 2020. Accordingly, the issue of immigrants, traffic and cleanliness at Silang Street has become the issues in materialising the objectives of this project.

eISSN: 2398-4287 @ 2020. The Authors. Published for AMER ABRA cE-Bs by e-International Publishing House, Ltd., UK. This is an open access article under the CC BYNC-ND license (http://creativecommons. org/licenses/by-nc-nd/4.0). Peer-review under responsibility of AMER (Association of Malaysian Environment-Behaviour Researchers), ABRA (Association of Behavioural Researchers on Asians) and cE-Bs (Centre for Environment-Behaviour Studies), Faculty of Architecture, Planning \& Surveying, Universiti Teknologi MARA, Malaysia.

DOI: https://doi.org/10.21834/ebpj.v5iSI1.2321 


\subsection{Literature Review}

An extensive amount of literature has been published on the relationship between tourism and economic growth (Yerik Afrianto Singgalan, 2019, Syed Jawad Hussain Shahzad et. al., 2017, Tang, C.F. \& Salah Abosedra, 2015, Antonakakis N. et al., 2015). At a lower ground level, tourism manages to reduce income inequality (Hengyun Li et al. 2016) and alleviate poverty (Adam Blake et al 2008).

The high population of immigrants, legal or illegal contributes towards tourists' perception on the area of destination. They may likely have negative attitudes toward immigrants, which concerns on criminal activity that may threaten their safety and lifestyle security (Fateh Habibi, 2018, Simpson et al. 2016). Simpson et al. (2016) also mentioned that attitudes toward undocumented immigrants are also likely to affect travellers' perceived safety in the destination, the likelihood of recommending the area to others and their return intention to that area. Moufakkir (2014) proposed that animosity towards immigrants affects intention to visit the country of origin of the said group (the immigrants) for tourism purposes. Shafaqat Mehmood, Zahid Ahmad, \& Ather Azim Khan (2016) believed that when immigrants are not able to obtain economic success by legitimate means, they often got involved in illegal activities. In many cases, where the legitimate work of immigrants may not be enough to sustain them, it can then lead them towards participation in illegal activities. There is a likelihood of an increase in crime rates when immigrants displace local people within the job market. When many immigrants receive jobs in a specific area, thus depriving the local people of jobs, they may, to ensure their status quo, commit deviant acts. Thus, the rising number of immigrant workers brings more harm and have a negative impact to society in the long-term (Muhamad Badri Othman, 2015). On the other hand, Balli et al. (2016) studied the nexus between immigrant and tourism in a different perspective, whereby they concluded that tourists would visit immigrants' home countries with higher standards of institutional quality, civil liberty and freedom. Again, the issue centralises on the aspect of security.

According to Berry and Hau (2016), when immigrants remain attached to their heritage culture and also become involved in their new society, they achieve a greater level of wellbeing. In sharp contrast, when they are disengaged from both cultures, lacking bonding and bridging capital, they have poorer outcomes. This will determine how long the immigrants would stay in one place. If the immigrants feel comfortable living and surviving in one area, it will be unlikely for them to leave that place. Therefore, the government must emphasise this matter in regulating immigrants' activities, especially in Kuala Lumpur. Moufakkir (2014) states that tourism can be used as a political tool in so many ways, including policy-making and planning, sustainable development, travel restrictions, empowerment and development, destination marketing and public relations, as well as political and ideological reasons. As suggested by Simpson et al. (2016) and Milan et al. (2016), security is the main issue which the tourists will consider before embarking on a vacation at any place that is full of immigrants. Hence, to maintain the flow of tourists, the government should formulate and reinforce security measures that will give confidence to the tourists.

Although pieces of literature on the relationship between tourism and economic development and relationship between perceived risks which influenced tourists' interest to visit have arisen, so far there is no reported study on the aspect of regulating immigrants in tourism destinations and the relationship between immigrants at the Silang Street and its effect on tourists' inclination to visit Kuala Lumpur. Hence, the research fills in the gap in the literature by discussing the application of planning law in regulating immigrants' activities at Silang Street, Kuala Lumpur as part of the heritage-tourism destination.

\subsection{Methodology}

This research has adopted a mixed method, which is a combination of qualitative and quantitative methods. For the qualitative method, primary and secondary data were collected and analysed in obtaining an in-depth understanding of this issue (Nuraisyah Chua Abdullah, 2018). Primary data for this research was obtained through a semi-structured interview with the relevant officers from the various departments in Kuala Lumpur City Hall. The interviews were made with the officers from the Planning Department, Enforcement Department and Department of Permit and Licensing, Kuala Lumpur City Hall.

The secondary data of this research relied on statutes, books, journal articles from the internet and information from the website of all relevant departments. Statistics and records of applicants for business licences were obtained from the Department of Permit and Licensing, Kuala Lumpur City Hall. The information pertaining to the registration of a company was obtained from the Companies Commission of Malaysia. Apart from that, participant observation is also used to allow researchers to observe events that respondents may be unable or unwilling to share.

For the quantitative method, this tradition is active in the field which involves the impact of the law on society (G.R. Mullane, 1998, S. Mechoulan, 2006). This research adopted a descriptive method. The combination of methods involves the collection, analysis, and integration of qualitative and quantitative data in this study (Sharlene Nagy Hesse-Biber, 2010). The researchers have used the qualitative study to generate a specific set of theories and then tested out these generated ideas on a more representative population (QUAL - QUAN) (Sharlene Nagy Hesse-Biber, 2010).

For data collection, questionnaires have been distributed to 50 tourists in some areas of Kuala Lumpur. The sample from the tourists' population has been identified by using convenience sampling. The questionnaire consists of three parts, namely, demographic characteristics, perception and opinion of tourists on the immigrant influx in the heritage zone of Kuala Lumpur, and perception and opinion of tourists towards heritage conservation and value. Likert scale is used in the second and third parts to measure the strength of an attitude or an opinion. It consists of questions which are simple, direct and easy to understand. 


\subsection{Findings}

\subsection{Qualitative Data}

Silang Street is a meeting place for the immigrants, the majority of whom are from Bangladesh, while the others are from Nepal and Myanmar. The issue of immigrants dominating the Silang Street is not only about the issue of permits and licences to operate businesses but also the cleanliness of Kuala Lumpur which falls under the jurisdiction of the Kuala Lumpur Lumpur City Hall. The issue should be seen from a broader perspective and involved many other stakeholders. It may begin with the higher demand for foreign workers thus involving permission from the Immigration Department, which opens the door to immigrants to enter Malaysia. It is then followed by the issue of immigrants who operate businesses, which then falls under the jurisdiction of Companies Commission of Malaysia.

Based on the observation made at Silang Street, it is evident that the immigrants are dominating the area operating restaurants, sundry shops and saloons. However, based on the interview made with the officer of the Department of Permit and Licensing, Kuala Lumpur City Hall, in most cases, the owner of the premises and businesses are Malaysians, but rent them out to the immigrants. In some cases, the immigrants claim that they are working for the shop owners who are Malaysians. Therefore, the enforcement officer has no case against the immigrants as they can provide valid permits and licences and the businesses operated are in line with the law. The statistics below show the number of Malaysians who apply for the licence increases every year, whereas the number of non-citizens who apply for the licence is still within control. However, the situation at the Silang Stree is vice versa.

\begin{tabular}{cccccccc}
\multicolumn{1}{c}{ Table 1: Statistic for the Application of Premise Licence Based on Nationality } \\
\hline Nationality & $\mathbf{2 0 1 1}$ & $\mathbf{2 0 1 2}$ & $\mathbf{2 0 1 3}$ & $\mathbf{2 0 1 4}$ & $\mathbf{2 0 1 5}$ & $\mathbf{2 0 1 6}$ & $\mathbf{2 0 1 7}$ \\
\hline Citizen & 7382 & 7392 & 6214 & 6486 & 12765 & 11678 & 10948 \\
Non-citizen & 467 & 494 & 543 & 524 & 349 & 173 & 317 \\
Permanent resident & 2 & 2 & 1 & 38 & 54 & 35 & 28 \\
\hline Total & 7851 & 7888 & 6758 & 7048 & 13168 & 11886 & 11293 \\
\hline (Source: Department of Permit and Licensing, Kuala Lumpur City Hall)
\end{tabular}

The local authority cannot solve the issue of the monopoly of business activities by the immigrants at Silang Street by way of enforcement alone. There is nothing much the local authority can do to take action against them, until and unless there is a violation of business registration and permit. In this case, it is the Malaysians themselves who contribute to the flourishing immigrants' businesses at Silang Street due to their willingness to enter into business transactions with the immigrants by renting or selling the businesses to them. Their business arrangement is personal and within the legal rights of the owner. The old buildings which may have heritage value do not hold much significance to these owners as compared to the profit they may earn from their dealing with the immigrants.

\subsection{Quantitative Data}

In order to investigate the perception and opinion of tourists towards Kuala Lumpur, questionnaires have been distributed to 50 respondents who are tourists in some areas of the city centre. They include people from Asia, Europe, America, Africa and Oceania. The demographic characteristics of these 50 respondents have been analysed based on their age, gender, occupation, highest education and nationality. Perception and opinion of the respondents on immigrant influx is analysed by using the Likert Scale. The scales are between Strongly Disagree, Disagree, Neutral, Agree and Strongly Agree. The statements from this part are:

Influx1- The immigrant influx affects the cleanliness of Kuala Lumpur.

Influx2- The immigrants have interfered with the business of local people.

Influx3- Immigrant activities have changed the social characteristics of the city.

Influx4- Health issue is a problem since some of the immigrants brought along diseases with them.

Influx5- Tourists feel insecure when they visit places crowded with immigrants.

Table 2: Mean on Perception and Opinion on Immigrant Influx

\begin{tabular}{ccccccccc}
\hline & $\mathrm{N}$ & $\begin{array}{c}\text { Range } \\
\end{array}$ & Minimum & Maximum & \multicolumn{2}{c}{ Mean } & Std. Deviation & Variance \\
Statistic & Statistic & Statistic & Statistic & Statistic & Std. Error & Statistic & Statistic \\
\hline Influx1 & 50 & 4 & 1 & 5 & 3.50 & .138 & .974 & .949 \\
Influx2 & 50 & 4 & 1 & 5 & 3.48 & .129 & .909 & .826 \\
Influx3 & 50 & 4 & 1 & 5 & 3.80 & .140 & .990 & .980 \\
Influx4 & 50 & 4 & 1 & 5 & 3.44 & .146 & 1.033 & 1.068 \\
Influx5 & 50 & 4 & 1 & 5 & 3.36 & .124 & .875 & .766 \\
Valid N (listwise) & 50 & & & & & & & \\
\hline
\end{tabular}

The mean for Influx1, Influx2, Influx3, Influx4 and Influx 5 are 3.44 to 3.80 which means the response is between Neutral and Agree. It shows that the respondents agree with the statements in this part. For perception and opinion of tourists towards heritage conservation and value, the Likert Scale also has been used in this part. The scales are between Strongly Disagree, Disagree, Neutral, Agree and Strongly Agree. The statements in this part are:

Heritage1: Buildings in Kuala Lumpur fulfil the criteria of heritage buildings.

Heritage2: The uniqueness of the heritage buildings is one of the reasons why tourists visit 
Malaysia.

Heritage3: The government well preserves the heritage buildings in Kuala Lumpur.

Heritage4: The immigrant influx affected heritage value.

Heritage5: New development in Kuala Lumpur affects the heritage conservation and value of the buildings.

Table 3: Mean on Perception and Opinion of the Tourists towards Heritage Conservation and Value

\begin{tabular}{ccccccccc}
\hline & $\mathrm{N}$ & Range & Minimum & Maximum & \multicolumn{2}{c}{ Mean } & Std. Deviation & Variance \\
& Statistic & Statistic & Statistic & Statistic & Statistic & Std. Error & Statistic & Statistic \\
\hline Heritage1 & 50 & 4 & 1 & 5 & 3.58 & .111 & .785 & .616 \\
Heritage2 & 50 & 3 & 1 & 4 & 3.26 & .156 & 1.103 & 1.217 \\
Heritage3 & 50 & 2 & 2 & 4 & 3.64 & .074 & .525 & .276 \\
Heritage4 & 50 & 4 & 1 & 5 & 3.22 & .132 & .932 & .869 \\
Heritage5 & 50 & 3 & 2 & 5 & 3.70 & .087 & .614 & .378 \\
Valid N (listwise) & 50 & & & & & & & \\
\hline
\end{tabular}

The mean for Heritage1, Heritage2, Heritage3, Heritage4 and Heritage5 are between 3.22 to 3.70 which means the response is between Neutral and Agree. It means that generally, the respondents agree with the statements in this part.

\subsection{Discussion}

\subsection{Roles of the local planning authority}

There are three competing ideologies in planning law, namely; the law exists and should be used to protect private property (this may be called the traditional common law approach to the role of law); the law exists and should be used to advance the public interest, if necessary, against the interest of private property (this may be called the orthodox public administration and planning approach to the role of law) and, the law exists and should be used to advance the cause of public participation against both the orthodox public administration approach to the public interest and the common law approach of the overriding importance of private property (McAuslan, 1980). In the opinion of McAuslan (1980), the law must be used to protect public interests, if necessary, against the interests of private property.

The local planning authority may interfere to determine whether property owner may develop and obtain a permit to conduct any business on their property. In line with this, the local planning authority has the authority to control and regulate all development activities conducted in the Kuala Lumpur City Centre. As Kuala Lumpur has an outstanding national heritage significance, its historic buildings need to be protected and preserved. In conserving heritage buildings, Kuala Lumpur City Hall has established Heritage Zones in order to ensure that buildings located in this zone will maintain their historical character or ambience as prescribed in the Kuala Lumpur Urban Design Guidelines (UDG). Even though buildings located at Silang Street are considered old, they are not zoned as a heritage zone. However, Silang Street is not covered or hidden from the sight of tourists. Though it is not part of the heritage trail, tourists do pass through this street.

The aspects which the local authority seriously control are on cleanliness and rules on advertisement boards. Criticisms were made against Kuala Lumpur City Hall due to their failure in monitoring and enforcing the law on the immigrants. Based on the interview conducted, the issues on cleanliness and advertisement board are now under control. In fact, the Prohibition against Spitting (Federal Territory of Kuala Lumpur) By-Laws 2017 was passed on 15 March 2017 to give power to the local authority to penalise anyone who spits in the area. Anti-littering and regulation of advertisement boards and banners are also enforced. In controlling the use of language on the advertisement boards, the applicant of the licence for the premise and licence for advertisement board have to obtain approval from the Institute of Language and Literature Malaysia to check and approve the language used.

The enforcement aspect is far-reaching. The number of enforcement officers assigned to monitor all areas in Kuala Lumpur is not adequate. They also need to consider their safety especially when the area is dominated by immigrants for example, the Silang and Petaling Streets. This is perhaps one of the reasons for lack of enforcement in this area.

\subsection{Immigrant workers}

In achieving the high-income nation status in 2020, Malaysia depends upon labourers in various sectors (Muhammad Badri Othman, 2015). In relation to this, immigrant workers would be able to help solve the issue of lack of human resources from local people. Some employers prefer immigrant workers over local workers because the salary paid to the immigrants is cheaper. The issue escalates when the local workers demand higher salary due to increase in the living costs. Employers have the right to choose the cheapest human resources. The policy on hiring foreign workers is decided at the federal government level. It was decided, among others, that foreign workers should come from the approved source countries and under the specific sectors.

Accordingly, the foreign workers will only be allowed to enter Malaysia at the authorized entry points using visa with reference issued by the Immigration Department and entry visa issued by the Malaysian Attachés Office in the country of origin. The employers then must ensure that the clearance process of foreign workers at the entry points is done within 24 hours of the arrival time. The Visit Pass (Temporary Employment) VP(TE) will only be issued to the foreign workers after they have passed the FOMEMA medical examination within 30 days, where they have been certified fit by the clinic/ medical centre registered with FOMEMA. Should they fail the medical examination, the foreign worker will not be allowed to stay and work in this country. Issuance of VP(TE) shall be made at the Immigration Office. According to section 6(3) of the Immigration Act 1959/63 (Act 155), living and staying in Malaysia without a valid pass or permit 
is an offence. Therefore, in relation to the immigrants in the Silang Street, once they have obtained a valid pass or permit, there is no reason for them to fear for detention and free to work in this area. Some of the immigrants may hold only workers pass, but in actual fact, they also own businesses in these areas.

\subsection{Registration of Business}

Business includes every form of trade, commerce, craftsmanship, calling, profession or other activities carried on for gain, but does not include any office or employment or any charitable undertaking or any occupation specified in the Schedule of the Registration of Businesses Act 1956 (ROBA 1956) \& ROBA Rules 1957. The types of business are sole proprietorship and partnership. Business may be registered using a personal name or a trade name. The applicant is required to complete the Business Registration Form (Form A) with a list of information, namely; the business name, commencement date of business, principal place of business, the address of the branch of business (if any), information of owner and partners, type of business carried out and a copy of the Partnership Agreement (if any). Every business owner and partner must sign the completed form and be present at the counter for registration. The applicant should also be notified that although businesses have been registered with Companies Commission of Malaysia (SSM), business owners are responsible to obtain licences, permits or approval letters from other relevant authorities in order to operate their businesses.

\subsection{Conclusion and Recommendations}

In conclusion, most of the tourists visiting Kuala Lumpur are of the opinion that the immigrant influx affects the cleanliness, interferes with the business of local people, changes the social characteristics of the city and increases health problems. The tourists also feel insecure when visiting places crowded with immigrants. The issue of immigrants dominating business activities in Kuala Lumpur has changed the character and ambience of the area. These changes may affect the perception of tourists, thus has the impact on the inclination of tourists to visit Kuala Lumpur.

The government may take a drastic action by issuing a policy that the Silang Street or all streets in the City Centre should be free from premises which are operated by immigrants. In drafting the development plan for Kuala Lumpur, the local planning authority should take into consideration the fourth pillar, which is the element of culture in sustainable development. The local government should promote a model of development that meets the needs of the present generation without compromising the ability of future generation to meet their own needs as well as ensuring the enjoyment of culture and its components by all. Even though the buildings at the Silang Street have not been affected by development, its culture has changed with the widespread presence of immigrants. Finally, the entry of foreign workers should be controlled, and it is time for Malaysian property or business owners in areas such as the Silang Street to be patriotic in considering the impact of these immigrant workers to the nation. When the number of immigrants in Kuala Lumpur City Centre, especially in the tourism spot declines, it is easier for the local authority to regulate the area. The solutions to this issue still need to be highlighted and dealt by the top management, i.e. the Federal government, which will determine the economic development for its people.

\section{Acknowledgments}

The authors gratefully acknowledge the assistance of Universiti Teknologi MARA in providing the LESTARI grant (Project Number: 600IRMI/MyRA 5/3/LESTARI(0138/2016). The authors are also thankful to officers in Kuala Lumpur City Hall for their contribution and cooperation.

\section{References}

Avraham, E. (2004). Media strategies for improving an unfavourable city image. doi:10.1016/j.cities.2004.08.005

Balli, F., Balli, H.O., \& Louis, R.J. (2016). The impacts of immigrants and institutions on bilateral tourism flows. Tourism Management, 52, 221-229.

Berry, J.W., \& Hau, F. (2016). Immigrant Acculturation and Wellbeing in Canada. Canadian Psychology, 57 (4), $254-264$.

Cherifi, B., Smith, A., Maitland, R., \& Stevenson, N. (2014). Destination images of non-visitors. Annals of Tourism Research. 49, $190-202$.

Chor Foon Tang, Eu Chye Tan. (2015). Does Tourism Effectively Stimulate Malaysia's Economic Growth?.Tourism Management. 46, $158-163$.

Fateh Habibi, Mehran Rahmati \& Adel Karemi (2018). Contribution of Tourism to Economic Growth in Iran Provinces: GDM Approach. Future Business Journal. Vol 4 issue 2, 261-271.

L. Epstein and G. King. (2002). Empirical Research and the Goals of Legal Scholarship: The Rules of Inference. University of Chicago Law Review,1,69.

Milan, O.C., Simpson, J.J., Simpson, P.M., \& Choi, W. (2016). Reassurance or reason for concern: Security forces as a crisis management strategy. Tourism Management, 56, 114-125.

Muhammad Badri Othman. (2015). Strategies in the prevention of the influx of illegal immigrant workers in Malaysia, Conference Paper presented at8th Kuala Lumpur International Business, Economics and Law Conference, at Kuala Lumpur. DOI: 10.13140/RG.2.1.1355.5288. 
Norsiah Kadir \& Mohd Zaini Abd Karim (2012). Tourism and Economic Growth in Malaysia: Evidence from Tourist Arrivals from Asean-S Countries. Economic Research Ekonomskalstraživanja. 25:4, 1089-1100, DOI: 10.1080/1331677X.2012.11517550

Nuraisyah Chua Abdullah. (2018). Legal Research Methodology. Sweet \& Maxwell Malaysia.

Omar Moufakkir. (2014). What's immigration got to do with it? Immigrant animosity and its effects on tourism. Annals of Tourism Research, 49, $108-121$.

Parmjit Singh, Chan Yuen Fook\&Gurnam Kaur Sidhu. (2006). A Comprehensive Guide to Writing A Research Proposal. Venton Publishing.

ShafaqatMehmood, Zahid Ahmad, \&AtherAzim Khan. (2016). Dynamic relationships between tourist arrivals, immigrants, and crimes in the United States. Tourism Management, 54, 383-392.

Sharlene Nagy Hesse-Biber. (2010). Mixed Methods Research: Merging Theory with Practice. New York: The Guilford Press.

Simpson, J.J., Simpson, P.M., \& Milan, O.C. (2016). Attitude towards immigrants and security: Effects on destination-loyal tourists. Tourism Management, 57, $373-386$.

Uma Sekaran. (1992). Research Methods for Business: a Skill Building Approach (2nded). U.S.: John Wiley \& Sons.

Wing Hong Chui. (2007). Quantitative Legal Research. In Mike McConville\& Wing Hong Chui (Eds.). Research Methods for Law, Edinburgh University Press.

Yerik Afrianto Singgalen, Gatot Sasongko \& Pamerdi Giri Wiloso (2019). Efforts to Achieve Environmental Sustainability through Ecotourism, Journal of Indonesian Tourism and Development Studies, e-ISSN: 2338-1647.

Yip Yoke Teng, Living alongside KL Heritage, Thursday 20 June 2013 at http://www.thestar.com.my/news/community/2013/06/20/living-alongside-kl-heritage-big-plansunder-way-to-beautify-the-oldest-parts-of-the-city/ retrieved on 10 July 2017. 